\title{
Generation and Characterization of Cold Atmospheric Pressure Plasma Jet for Surface Modification of High- Density Polyethylene
}

Hom Bahadur Baniya, Rajesh Prakash Guragain, Santosh Dhungana, Gobinda Prasad Panta, Niroj Basnet, Binita Sedhai, Binod Baniya, and Deepak Prasad Subedi

Journal of Nepal Physical Society

Volume 7, No 3, 2021

(Special Issue: ANPA Conference, 2021)

ISSN: 2392-473X (Print), 2738-9537 (Online)

\section{Editors:}

Dr. Nabin Malakar (Editor in chief)

Worcester State University

Dr. Pashupati Dhakal

Thomas Jefferson National Accelerator Facility, USA

Dr. Arjun Dahal

University of South Alabama, USA

Dr. Chiranjivi Lamsal

SUNY Platsburgh, USA

Dr. Dilli Raj Paudyal

University of Regina, Canada

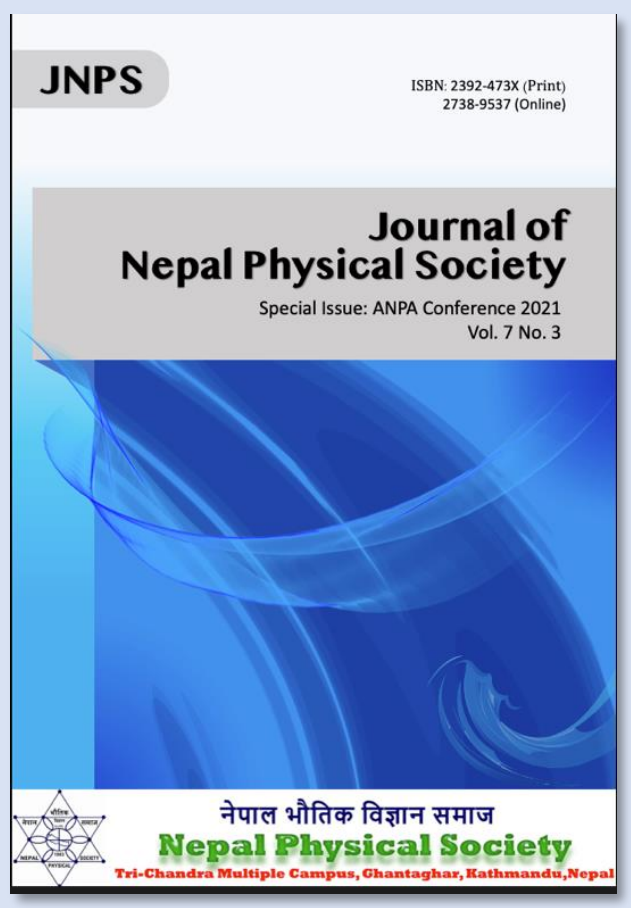

Managing Editor:

Dr. Binod Adhikari

St. Xavier's College, Kathmandu, Nepal

JNPS, 7 (3), 41-46 (2021)

DOI: http://doi.org/10.3126/jnphyssoc.v7i3.42190

Published by: Nepal Physical Society

P.O. Box: 2934

Tri-Chandra Campus

Kathmandu, Nepal

Email: npseditor@gmail.com 


\title{
Generation and Characterization of Cold Atmospheric Pressure Plasma Jet for Surface Modification of High- Density Polyethylene
}

\author{
Hom Bahadur Baniya ${ }^{1,2}$ *, Rajesh Prakash Guragain ${ }^{1}$, Santosh Dhungana ${ }^{1}$, \\ Gobinda Prasad Panta, Niroj Basnet ${ }^{1}$, Binita Sedhai ${ }^{1}$, Binod Baniya ${ }^{3}$, and Deepak Prasad Subedi ${ }^{1}$ \\ ${ }^{I}$ Department of Physics, School of Science, Kathmandu University, Dhulikhel, Nepal \\ ${ }^{2}$ Department of Physics, Tri-Chandra Multiple Campus, Tribhuvan University, Kathmandu, Nepal \\ ${ }^{3}$ Department of Environmental Science, Patan Multiple Campus, Tribhuvan University, Nepal \\ EEmail: hom.baniya@trc.tu.edu.np; hombaniya@gmail.com
}

\begin{abstract}
Cold atmospheric pressure plasma technology has a variety of applications in different fields including material science and biomedical science. It has been using for surface modification and material processing in material science and used to improve the wettability, adhesion and biocompability of polymeric surfaces without altering the entire bulk properties. This paper outlines the characterization of cold atmospheric pressure plasma jet, which was generated in a high frequency $(20 \mathrm{kHz})$ and high voltage $(3.5 \mathrm{kV})$ power supply, as well as its application in the surface modification of high-density polyethylene. Electrical and optical characteristics are used to estimate the electron density of the plasma. The effect of plasma on the surface properties of the material are analyzed by calculating contact angle, surface energy measurements and analyzing scanning electron microscopy images. Adhesive bonding strength and numerous other attributes have increased, however surface treatment is the process of cleaning, etching, functionalizing, and chemically treating substrates to improve roughness and adhesive properties on the surface. Cold plasma can induce a soft roughening on the surface through ion bombardment with polar functional groups resulting in the decrease in water contact angle.
\end{abstract}

\section{Received: Aug 8, $2021 \quad$ Revised: Sept 27, 2021 Accepted: Dec 2, 2021}

Keywords: Wettability, Surface energy, High density polyethylene (HDPE), Scanning electron microscopy (SEM)

\section{INTRODUCTION}

Over the years, a large number of techniques have been developed to study different aspects of the physics and chemistry of surfaces; however, a few have been found many applications such as material processing, biomedical material processing and thin film deposition in basic surface science and applied surface analysis [1]. Atmospheric-pressure plasmas are highly used in materials processing with compared to traditional sources like plasma torches, corona discharges etc. Cold atmospheric pressure plasma jet (CAPPJ) is a gamma mode resonant cavity plasma discharge, which can execute at atmospheric pressure and temperature close to room temperature. Beside the conventional sources of plasma production like transferred arcs, plasma torches, and corona discharge, the CAPPJ produces a gas phase and shows distinct non-thermal characteristics. It is relatively safety for operation than other plasma producing conventional devices. Plasma consists of ions, free electrons, free radicals, excited species, neutrals and photons showing collective behaviors $[2,3]$. These plasma species are responsible for surface modification by adding or etching functional groups on the substrate. Plasma treatment of polymer has been considered as the best way of surface modification technique because it is dry, environmental 
friendly, simple to operate, and can be done at low temperatures [4].

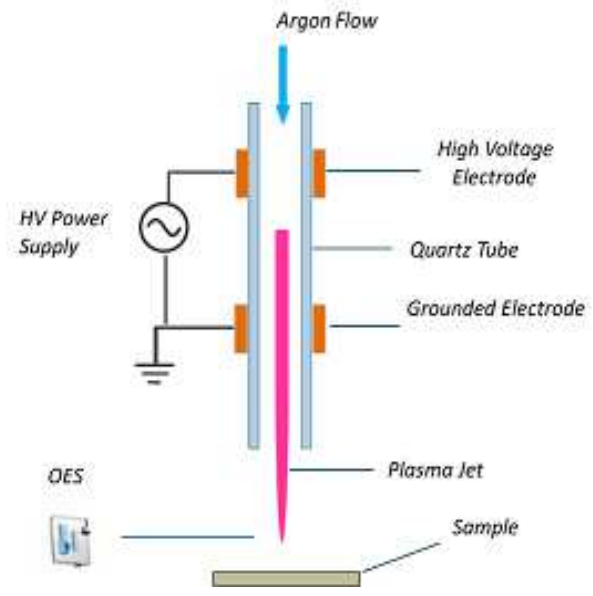

(a)

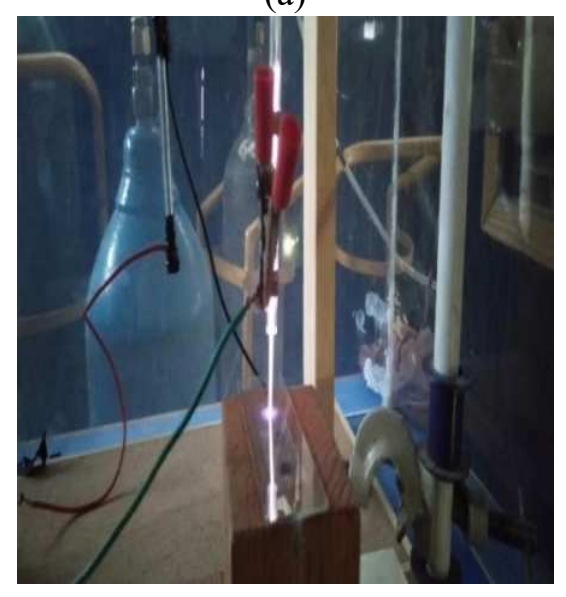

(b)

FIGURE 1: (a) Diagrammatic representation of the experimental setup and (b) Photograph of the discharge[13]

Polymers are generally macromolecules formed by repeated linkage of large number of small molecules [5]. Polymeric materials have been utilized to replace traditional engineering materials because of their high strength-to-weight ratio, outstanding corrosion resistance, recycling potential, exceptional fracture resistance, superb transparency, minimal flammability, and low price $[6,7]$. They have been used for the variety of applications in many technological fields. Because polymers are hydrophobic and have low surface energy materials, they do not cling well to other materials. It is important to raise the surface free energy without altering the bulk properties of the polymer $[8,9]$. The use of an atmospheric pressure plasma jet to treat polymers has grown in popularity in recent years [10].
Surface modification by plasma jet is responsible for modifying the surface morphology without changing the inherent properties by introducing adhesion of polar functional groups on the polymer surface $[11,12]$. The main objective of this research is that the majority of prior experiment used RF power source which is more costly compared than the one utilized in this study. As a result, a low-cost device made to produce cold plasma jet at atmospheric pressure having potential applications in material processing has been created. Using same device, plasma treatment to high density polyethylene (HDPE) samples and their surface properties have been reported. High density polyethylene is highly used polymer in industries, medicine, and biomedical applications because of its mechanical characteristics, flexibility, and chemical durability. However, due to its low surface energy and absence of functional groups, HDPE has a partly hydrophobic surface, resulting in limited adhesion and chemical reactivity $[12,13]$.

\section{MATERIALS AND METHODS}

The experimental setup and photograph of the discharge are shown in figure 1 . The experimental set up consists of capacitive coupled electrode system made of from copper foil wrapped around a borosilicate glass tube of outer diameter $4 \mathrm{~mm}$ and inner diameter $3 \mathrm{~mm}$. The electrode is connected to high voltage power supply at working voltage $3.5 \mathrm{kV}$. The distance between two electrodes is maintained at $5 \mathrm{~cm}$ and the distance between the tip of the nozzle and lower electrode is kept $0.3 \mathrm{~cm}$. Argon gas of flow rate $3 \mathrm{~L} / \mathrm{min}$ and ac power supply $(3.5 \mathrm{kV}, 20 \mathrm{kHz})$ were maintained during the experiment. Current probe, PINTEX HVP-28HF and oscilloscope TEKTRONIX TDS2002 are used for the measurement of electrical signals. Optical characterization of the discharge is analyzed with the help of optical emission spectrometer (USB 2000+, Ocean Optics). Application of plasma jet for the treatment of high density polyethylene (HDPE) samples are studied by varying treatment time. We have chosen HDPE samples to study surface properties after plasma treatment. In this work, the contact angles are measured at four different points of the samples. The average value of the contact angle is used for the determination of surface energy. Zeiss Field-emission scanning electron microscope (SEM) is used to examine the surface morphology of polymer surfaces. 


\section{RESULTS AND DISCUSSION}

\section{Electrical characterization of CAPPJ}

Power balance method is commonly used for the determination of electron density in glow mode of the discharge. As the glow mode, discharge is uniformly distributed over the electrode area. This method is based on the conservation of energy that is energy lost by plasma components is equal to energy gained by plasma from applied power source. Estimation of electron density is done by power balance method. Here, power consumption per cycle of discharge can be written as $P_{a v}=2 A n_{e} v_{b} E_{\text {lost }}$.

Where, $2 A n_{e} v_{b} E_{\text {lost }}$ represents the total power of the discharge, A be the area of the electrode and $v_{b}$ being the Bohm velocity. Hence, Electron density is formulated as

$$
n_{e}=\frac{P_{a v}}{2 A v_{b} E_{\text {lost }}}
$$

This equation can be used to determine the electron density in glow mode of discharge [14].

Figure 2 shows the current and voltage waveform of the discharge. Using the values of applied voltage and average discharge current, the electron density is determined using the above equation. Using the value of Bohm velocity, $v_{b}=2 \times 10^{3} \mathrm{~m} / \mathrm{sec}$ [15] (almost constant in case of argon discharge) energy lost, $\mathrm{E}_{\text {lost }}=$ $50 \mathrm{eV}$ and electrode area $\mathrm{A}=12.56 \times 10^{-6} \mathrm{~m}^{2}$, the electron density $\left(\mathrm{n}_{\mathrm{e}}\right)$ was found to be $1.74 \times 10^{14} \mathrm{~cm}^{-3}$.

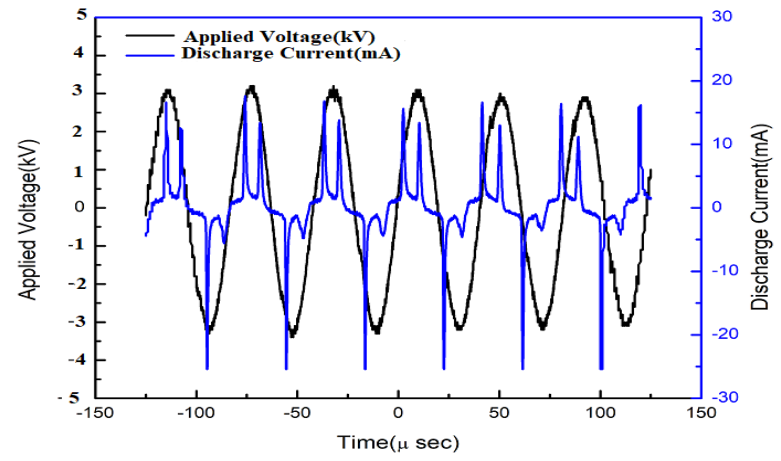

FIGURE 2. Current voltage graph at argon flow $\operatorname{rate}(\mathrm{Q})=3$ $\mathrm{L} / \mathrm{min}$ at an applied voltage of $3.5 \mathrm{kV}$

\section{Optical characterization of CAPPJ}

The emission spectra of the discharge are also used to determine electron density $\left(n_{e}\right)$, using Stark broadening method $[16,17]$. In this method, argon line of $697.299 \mathrm{~nm}$ is chosen from figure 3 .

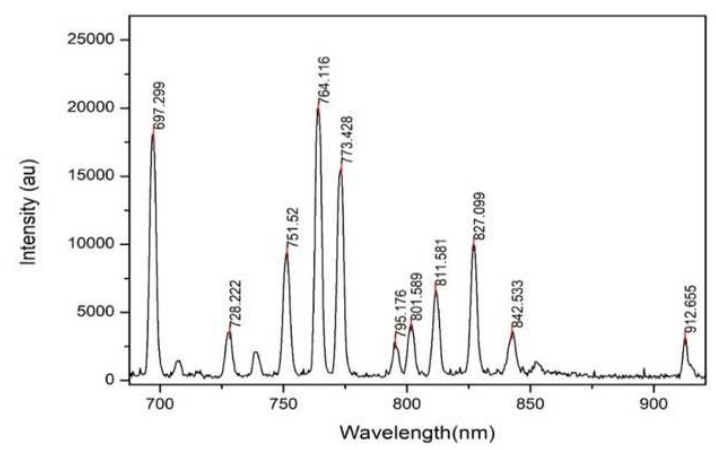

FIGURE 3. Spectra of the discharge at frequency $20 \mathrm{kHz}$ and an applied voltage of $3.5 \mathrm{kV}(\mathrm{Q}=3 \mathrm{~L} / \mathrm{min})$

The electron density is related to FWHM according to the relation represented by equation (2).

$\Delta \lambda_{\text {Stark }}=2 \times 10^{-11} n_{e}^{2 / 3}$

By deconvolution of Ar I line (697.299 nm) and made Lorenzian fitting, the value of $\Delta \lambda_{\text {Stark }}$ is found to be $1.461 \mathrm{~nm}$. Substituting the value of $\Delta \lambda_{\text {Stark }}$ in equation (2), the corresponding electron density is found to be of the order of $10^{16} \mathrm{~cm}^{-3}$.

\section{Surface modification of high density polyethylene (HDPE)}

\section{Contact angle and surface energy measurements}

Contact angle is the angle made by tangent line at the contact point of liquid on the solid surface. The effect of cold plasma jet treatment was assessed by comparing the contact angle of the untreated and treated samples of different polymers with doubly distilled water. Sessile drops of volume $4 \mu 1$ were made using a standard micro-syringe. The contact angle of drops with the surface of the polymer sheet was measured using a "Rame-Hart" contact angle goniometer model 200. This unit is equipped with standard software (drop image software) to analyze the drop image for the calculation of surface energy. For the smooth and homogeneous surface, at equilibrium condition, the contact angle and surface energy were measured using the Young's 
equation and Owens Wendt Kaeble methods respectively $[18,19]$.

$$
\cos \theta=\frac{\gamma_{s v}-\gamma_{s l}}{\gamma_{l v}}
$$

Where, $\gamma_{s v}$ is the surface free energy of the solid substrate $\gamma_{s l}$ is the interfacial tension between the solid and the liquid and $\gamma_{l v}$ is the surface tension of the liquid.

For two liquids $i$ and $j$,

$$
\gamma_{l i}\left(1+\cos \theta_{i}\right)=2\left(\gamma_{l i}^{d} \gamma_{s}^{d}\right)^{\frac{1}{2}}+2\left(\gamma_{l i}^{p} \gamma_{s}^{p}\right)^{\frac{1}{2}}
$$

$$
\gamma_{l j}\left(1+\cos \theta_{j}\right)=2\left(\gamma_{l j}^{d} \gamma_{s}^{d}\right)^{\frac{1}{2}}+2\left(\gamma_{l j}^{p} \gamma_{s}^{p}\right)^{\frac{1}{2}}
$$

By solving equations (4) and (5) with known values of surface tension and its polar and dispersion components of the test liquids, components of surface energy of the solid, can be calculated. The sum of these two quantities gives the total surface energy of the solid.

Figure 4(a) shows the change in contact angle of HDPE samples with treatment time. The influence of this parameter on the hydrophilicity was investigated, using a "Rame-Hart" contact angle goniometer. Initially, contact angle of the untreated HDPE for water and glycerol were $94^{\circ}$ and $83.5^{\circ}$ but after plasma treatment contact angles were effectively reduced to $53^{\circ}$ and $52.5^{\circ}$ and almost saturated after 20 second treatment time. The reduction in contact angle might be due to increase roughness on the surface by sputtering phenomenon. Figure 4(b) depicts the variation of surface energy along with polar and dispersion components with treatment time on the surface of HDPE. Initially, total surface energy along with polar and dispersion components (polar component about $8 \mathrm{~mJ} / \mathrm{m}^{2}$ and dispersion component about $17 \mathrm{~mJ} / \mathrm{m}^{2}$ ) is $25 \mathrm{~mJ} / \mathrm{m}^{2}$. CAPPJ treatment after 15 seconds, surface energy was effectively increased(polar component to $40 \mathrm{~mJ} / \mathrm{m}^{2}$ and dispersion component almost constant about $17.5 \mathrm{~mJ} /$ $\mathrm{m}^{2}$ ) to $57.5 \mathrm{~mJ} / \mathrm{m}^{2}$ and almost saturated up to 120 seconds treatment time. The polar component shows a similar tendency to the total surface energy, which is mostly owing to the inclusion of polar functional groups on the treated HDPE surface. The dispersion component initially decreases and become constant $[19$, 20].

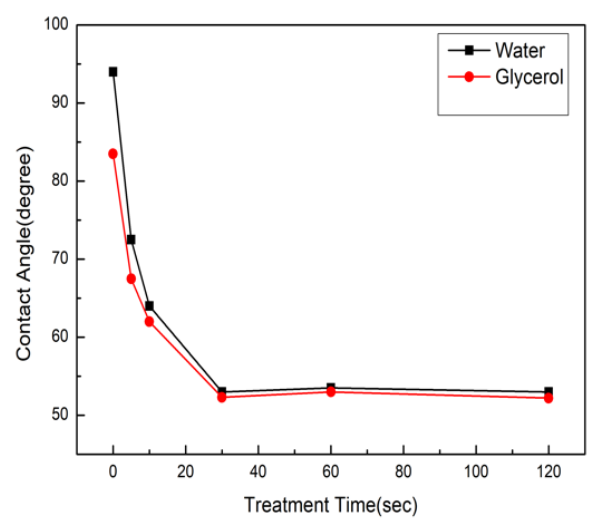

(a)

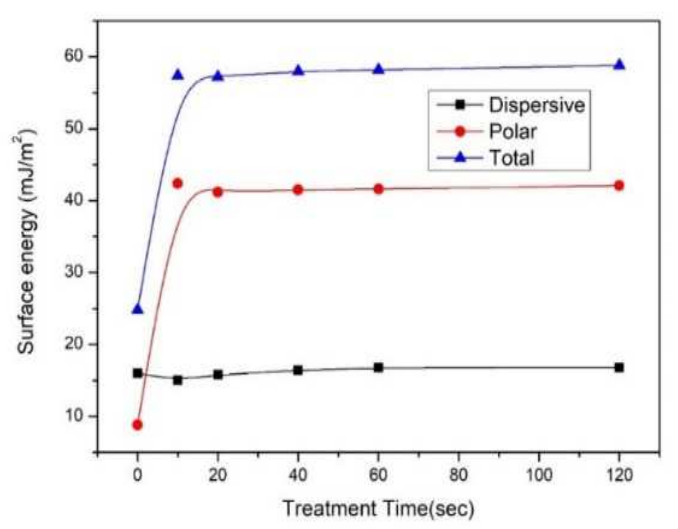

(b)

FIGURE 4: Variation of (a) contact angle of water and glycerol and (b) total surface energy along with polar and dispersion components on the surface of HDPE with treatment time $(20 \mathrm{kHz}, 3.5 \mathrm{kV}$ and $3 \mathrm{~L} / \mathrm{min})$

\section{SEM analysis}

Figure 5 shows the SEM morphology of (a) control and (b) plasma treated samples of HDPE at 60 seconds. The change in surface roughness of the sample after treatment was studied by scanning electron microscopy (SEM). SEM images of the control and treated samples clearly demonstrate that the plasma treatment significantly increases the surface roughness.

The scanned image demonstrates that there is significantly change in surface morphology after treatment. Thus, comparing both SEM images of untreated and treated samples it can be concluded that 
the plasma treatment plays vital role to increase the roughness of the HDPE surface. The main cause of the increase in roughness is due to the etching and removable of top monolayer of the polymer surface by CAPPJ treatment [21, 22].
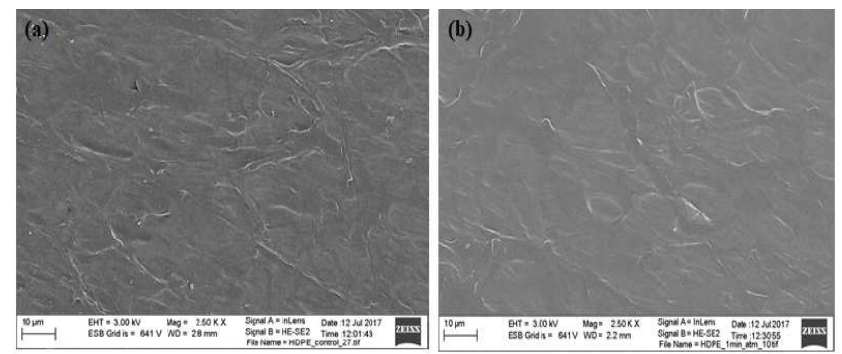

FIGURE 5. SEM image of (a) control and (b) plasma jet treated samples of HDPE

\section{CONCLUSIONS}

Cold atmospheric pressure argon plasma jet has been produced and characterized by optical and electrical methods. Electron density $\left(n_{e}\right)$ was found to be of the order of $10^{14} \mathrm{~cm}^{-3}$ and $10^{16} \mathrm{~cm}^{-3}$ using power balance and stark broadening methods respectively. The discrepancy in the measurement of electron density via electrical and optical methods required more study to know the reason behind this, which can be considered as future works. Treatment of high-density polyethylene by cold plasma jet resulted in enhancement on hydrophilicity. It is mainly due to incorporation of the polar functional groups in the polymer surface after plasma treatment. The improvement of wettability of polymer samples strongly depends on the treatment time and etching rate. During the experiment, contact angle of polymer after plasma jet treatment was found to be decreased effectively, whereas corresponding surface energy was increased. Scanning electron microscopy images of the control and treated samples clearly demonstrate that the plasma treatment significantly increases the surface roughness.

\section{ACKNOWLEDGEMENTS}

The authors would like to thank Prof. Andrzej Huczko from University of Warsaw, Poland for the SEM analysis of the polymer samples.

\section{EDITOR'S NOTE}

This manuscript was submitted to the Association of Nepali Physicists in America (ANPA) Conference 2021 for publication in the special issue of Journal of Nepal Physical Society.

\section{REFERENCES}

1. Owens, D. K.; Wendt, R.C. Estimation of the surface free energy of polymers. Journal of Applied Polymer Science, 1969, 13, 1741- 1747.

2. Chen, F. F.; Evans, J. D.; Zawalski, W. Electric Probes, In Plasma Diagnostic Techniques. R. H. Huddle stone, \& S. L. Leonard (Eds.), New York, USA: Academic Press. 1965, 113-200.

3. Dhungana, S.; Guragain, R. P.; Baniya, H. B.; Panta, G. P.; Chhetri, G. K.; Subedi. D. P. Electrical and Optical Characterization of Gliding Arc Discharge (GAD) Operated at Line Frequency $(50 \mathrm{~Hz})$ Power Supply. Journal of Nepal Physical Society, 2020, 6(2), 26-33.

4. Deynse, A. V.; Morent, R.; Geyter, N. D. Surface Modification of Polymers Using Atmospheric Pressure Cold Plasma Technology. Polymer science: research advances, practical applications and educational aspects, 2016: 506-516.

5. Friedrich, K. Polymer composites for tribological applications. Advanced Industrial and Engineering Polymer Research, 2018, 1(1), 3-39.

6. Sarani, A.; Nikiforov, A. Y.; Geyter, N. D.; Morent, R.; Leys, C. Surface modification of polypropylene with an atmospheric pressure plasma jet sustained in argon and an argon/water vapor mixture. Applied Surface Science, 2011, 257(20), 8737-8741.

7. Mercado-Cabrera, A.; Jaramillo-Sierra, B.; LopezCallejas, R.; Alvarad, R.; de la Piedad-Beneitez, A.; PenaEguiluz, R.; Barocio-Delgado, S.; Munoz-Castro, A.; Rodriguez, B. Surface modification of polypropylene fiber for hydrophilicity enhancement aided by DBD. Plasma Progress in Organic Coatings, 2013, 76(12), 1858-1862.

8. Baniya, H. B.; Shrestha, R.; Shrestha, A.; Shrestha, S.; Gurung, J. P.; Shrestha, A. K.; Subedi, D. P. Surface modification of polycarbonate by atmospheric pressure argon/air plasma jet. Kathmandu University Journal of Science, Engineering and Technology (KUSET), 2014, 10(2), 13-16.

9. Joshi, U.M.; Subedi, D.P. Surface treatment of polypropylene (PP) film by $50 \mathrm{~Hz}$ dielectric barrier discharge produced in air and argon/air mixture at atmospheric pressure. AIP Conference Proceedings, 2015, 1670 (1), 1-4.

10. Baniya, H. B.; Shrestha, R.; Guragain, R. P.; Kshetri, M. B.; Pandey, B. P.; Subedi, D. P. Generation and characterization of an atmospheric pressure plasma jet (APPJ) and its application in the surface modification of polyethylene terephthalate. International Journal of 
Polymer Science, $\mathbf{2 0 2 0} \quad 1-7, \quad$ (2020), https://doi.org/10.1155/2020/9247642.

11. Noeske, M.; Degenhardt, J.; Strudthoff, S.; Lommatzsch, U. Plasma jet treatment of five polymers at atmospheric pressure: surface modifications and the relevance for adhesion. International Journal of Adhesion and Adhesives, 2004, 24(2), 171-177, https://doi.org/10.1016/j.ijadhadh.2003.09.006.

12. Sasmazel, H. T.; Alazzawi. M.; Alsahib. N. K. A. Atmospheric pressure plasma surface treatment of polymers and influence on cell cultivation. Molecules, 2021, 26, 1-25.

13. Baniya, H. B.; Guragain, R. P.; Subedi, D. P. Cold atmospheric pressure plasma technology for modifying polymers to enhance adhesion: A critical review. Reviews of Adhesion and Adhesives, 2021, 9(2), 269- 307, https://doi.org/10.7569/RAA.2021.097306.

14. Balcon, N.; Aanesl, A.; Boswell, R. Pulsed RF discharges, glow and filamentary mode at atmospheric pressurein argon. Plasma Sources Science and Technology, 2007, 16(2), 217-225, https: //doi.org/101088/0963-0252/16/2/002.

15. Wong, C.S. and Mongkolnavin, R. Plasma diagnostics techniques, In: Elements of Plasma Technology. Springer Briefs in Applied Sciences and Technology, Springer (2016).

16. Baniya, H. B.; Guragain, R. P.; Baniya, B.; Subedi, D. P. Cold atmospheric pressure plasma jet for the improvement of wettability of polypropylene. International Journal of Polymer Science, 2020, 1-9, https://doi.org/10.1155/2020/3860259.
17. Falahat, A.; Ganjovi, A.; Taraz, M.; Ravari, M. N. R.; Shahedi, A. Optical characteristics of a RF DBD plasma jet in various $\mathrm{Ar} / \mathrm{O}_{2}$ mixtures. J. Physics, 2018, 90, 27, https: //doi.org/10.1007/s12043-018-1520-6.

18. Baniya, H. B.; Guraguin, R. P.; Baniya, B.; Subedi, D. P. Experimental study of cold atmospheric pressure plasma jet and its application in the surface modification of polypropylene. Rev. Adhesion Adhesives, 2020, 8(2), 1-14, https://doi.org/10.7569/RAA.2020.097304.

19. Yuan, Y.; Lee, T. R. Contact Angle and Wetting Properties, In G. Bracco, and B. Holst (Eds.), Springer Series in Surface Sciences, Springer, Berlin, Heidelberg, 2013; Volume 51, pp. 3-34.

20. Baniya, H. B.; Guragain, R. P.; Baniya, B., Qin, G.; Subedi, D. P. Improvement of hydrophilicity of polyamide using atmospheric pressure plasma jet. $J$. Physical Sciences, 2020, 17, 133-138.

22. Furukawa, T.; Sato, H.; Kita, Y.; Matsukawa, K.; Yamaguchi, H.; Ochiai, S.; Seisler, H. W.; Ozaki, Y. Molecular structure, crystallinity and morphology of polyethylene/polypropylene blends studied by Raman mapping, scanning electron microscopy, wide angle $\mathrm{X}$ ray diffraction, and differential scanning calorimetry. Polymer J., 2006, 38, 1127-1136.

23. Guragain, R. P.; Baniya, H. B.; Dhungana, S.; Gautam, S.; Pandey, B. P.; Joshi, U. M.; Subedi, D. P. Characterization of dielectric barrier discharge (DBD) produced in air at atmospheric pressure and its application in surface modification of high-density polyethylene (HDPE). J. Technol. Space Plasmas. 2020, 1, 27-35. 